\title{
Repeated Light-Dark Phase Shifts Modulate Voluntary Ethanol Intake in Male and Female High Alcohol- Drinking (HAD1) Rats
}

\author{
James W. Clark, Michael C. Fixaris, Gabriel V. Belanger, and Alan M. Rosenwasser
}

\begin{abstract}
Background: Chronic disruption of sleep and other circadian biological rhythms, such as occurs in shift work or in frequent transmeridian travel, appears to represent a significant source of allostatic load, leading to the emergence of stress-related physical and psychological illness. Recent animal experiments have shown that these negative health effects may be effectively modeled by exposure to repeated phase shifts of the daily light-dark (LD) cycle. As chronobiological disturbances are thought to promote relapse in abstinent alcoholics, and may also be associated with increased risk of subsequent alcohol abuse in nonalcoholic populations, the present experiment was designed to examine the effects of repeated LD phase shifts on voluntary ethanol intake in rats. A selectively bred, high alcohol-drinking (HAD1) rat line was utilized to increase the likelihood of excessive alcoholic-like drinking.

Methods: Male and female rats of the selectively bred HAD1 rat line were maintained individually under a LD 12:12 cycle with both ethanol $(10 \% \mathrm{v} / \mathrm{v})$ and water available continuously. Animals in the experimental group were subjected to repeated 6-hour LD phase advances at 3 to 4 week intervals, while control rats were maintained under a stable LD cycle throughout the study. Contact-sensing drinkometers were used to monitor circadian lick patterns, and ethanol and water intakes were recorded weekly.

Results: Control males showed progressively increasing ethanol intake and ethanol preference over the course of the study, but males exposed to chronic LD phase shifts exhibited gradual decreases in ethanol drinking. In contrast, control females displayed decreasing ethanol intake and ethanol preference over the course of the experiment, while females exposed to experimental LD phase shifts exhibited a slight increase in ethanol drinking.

Conclusions: Chronic circadian desynchrony induced by repeated LD phase shifts resulted in sex-specific modulation of voluntary ethanol intake, reducing ethanol intake in males while slightly increasing intake in females. While partially contrary to initial predictions, these results are consistent with extensive prior research showing that chronic stress may either increase or decrease ethanol intake, depending on strain, sex, stressor type, and experimental history. Thus, repeated LD phase shifts may provide a novel chronobiological model for the analysis of stress effects on alcohol intake.
\end{abstract}

Key Words: Chronobiology, Alcohol Intake, Selectively Bred Rats, Jet Lag, Stress, Sex Differences.

A $\mathrm{N}$ EXTENSIVE LITERATURE links alcohol intake to chronobiological regulation and dysregulation (Danel and Touitou, 2004; el-Guebaly, 1987a,b; Rosenwasser, 2001; Spanagel et al., 2005b). Thus, chronic alcoholism is associated with dramatic and widespread disturbances in both sleep and circadian physiology (Brower, 2001, 2003; Crum

From the Department of Psychology, University of Maine, Orono, Maine (JWC, MCF, GVB, AMR); and the Department of Biological Sciences, University of Maine, Orono, Maine (GVB, AMR).

Received for publication March 1, 2007; accepted June 21, 2007.

Reprint requests: Alan M. Rosenwasser, Department of Psychology, University of Maine, 5742 Little Hall, Orono, ME 04469-5742; E-mail:alanr@maine.edu

Supported by NIAAA AA13893 to AMR.

Copyright C 2007 by the Research Society on Alcoholism.

DOI: 10.1111/j.1530-0277.2007.00476.x et al., 2004a; Imatoh et al., 1986; Kodama et al., 1988; Kuhlwein et al., 2003; Landolt and Gillin, 2001; Schmitz et al., 1996). Further, both acute and chronic alcohol exposure alters various aspects of sleep and circadian rhythms in nondependent humans and in experimental animals (Danel et al., 2001; Ehlers and Slawecki, 2000; Kakihana and Moore, 1976; Kubota et al., 2002; Roehrs and Roth, 2001; Rouhani et al., 1990). In animals, these effects are known to include alterations in fundamental properties of the underlying circadian pacemaker, including free-running circadian period and responsiveness to photic and nonphotic phase-shifting stimuli (Dwyer and Rosenwasser, 1998; Mistlberger and Nadeau, 1992; Rosenwasser et al., 2005a,c). Such findings are probably mediated by the pharmacological effects of ethanol on neurotransmitter function and gene expression in the suprachiasmatic nucleus (SCN), site of the mammalian circadian pacemaker (Chen et al., 2004; Madeira et al., 1997). 
In addition to the effects of alcohol on sleep and circadian rhythms, reciprocal effects of chronobiological disruption on voluntary alcohol intake have also been documented. Thus, alterations in photoperiod or other features of the daily light-dark (LD) cycle modulate voluntary ethanol intake in rodents (Gauvin et al., 1997; Goodwin et al., 1999; Hiller-Sturmhofel and Kulkosky, 2001; Millard and Dole, 1983), and these effects appear to be mediated, in part, via alterations in circadian entrainment pattern rather than via differential light exposure per se (Millard and Dole, 1983). Further, chronic sleep disruption increases the likelihood of relapse in abstinent alcoholics (Brower, 2001, 2003; Crum et al., 2004a), and is also a risk factor for future alcohol abuse in nonalcoholic populations (Crum et al., 2004b; Wong et al., 2004). At the genetic level, mutations in identified circadian "clock genes" alter responsiveness to alcohol and other drugs of abuse and modulate drug-motivated behaviors (McClung et al., 2005; Spanagel et al., 2005a), while selectively bred alcohol-preferring rats display alterations in circadian pacemaker phenotype even when ethanol-naïve (Rosenwasser et al., 2005b). Taken together, these results implicate multiple and bidirectional causal mechanisms in the chronobiology of alcohol.

In this study, we examined the effects of repeated LD phase shifts on voluntary ethanol intake in selectively bred, high alcohol-drinking (HAD1) rats. Experimental LD phase shifts mimic the abrupt changes in illumination schedule associated with transmeridian travel or shift work schedules, and result in transient circadian desynchrony at the behavioral level (Aschoff et al., 1975), as well as in the expression of specific clock genes within distinct subnuclei of the SCN (Nagano et al., 2003; Nakamura et al., 2005; Reddy et al., 2002) and in peripheral tissues (Filipski et al., 2005; Yamazaki et al., 2000). Circadian desynchrony probably accounts for many of the negative effects implied by the term "jet lag" (Comperatore and Krueger, 1990; Redfern et al., 1994), and indeed, animal experiments have shown that chronic exposure to repeated LD phase shifts can have serious consequences for health and longevity (Davidson et al., 2006; Filipski et al., 2004, 2005; Kort and Weijma, 1982; Kort et al., 1986; Nelson and Halberg, 1986; Penev et al., 1998; Tsai et al., 2005). Similarly, chronic circadian desynchrony is thought to underlie, in part, the increased risk of medical and psychiatric disease in long-term shift-workers (Boulos and Rosenwasser, 2004; Comperatore and Krueger, 1990).

Boulos and Rosenwasser (2004) have argued that chronic circadian desynchrony represents a significant source of allostatic load, contributing to the emergence of stress-related disease in shift-workers and other affected individuals. Thus, exposure to repeated LD phase shifts may provide an experimental model for the chronic chronobiological stress associated with both shift work and jet lag, and may help to better understand the health implications of these prevalent conditions. In this context, an extensive body of research has linked both physical and psychosocial stressors to alcohol consumption in humans and experimental animals (Pohorecky, 1981, 1990, 1991; Sillaber and Henniger, 2004). This research area is rather complex, however, as stress has been reported to either increase or decrease voluntary ethanol intake, depending on numerous situational and organismal factors, including the type of stressor, the history of both stress and alcohol exposure, genetic background, sex, and ethanol preference phenotype (Bond, 1978; Chester et al., 2004, 2006; van der Kam et al., 2005; Lynch et al., 1999; Rockman and Glavin, 1986; Rockman et al., 1986; Vengeliene et al., 2003; Volpicelli et al., 1990).

In the present study, therefore, we sought to examine the effects of a novel chronobiological stressor-repeated LD phase shifts - on voluntary ethanol intake in male and female rats. As the initial expectation guiding this study was that chronic circadian desynchrony might promote increased ethanol intake, as has been hypothesized to occur in abstinent alcoholics and other human populations, we utilized a selectively bred line of genetically alcohol preferring (HAD1) rats to maximize the likelihood that excessive, alcoholic-like drinking might emerge.

\section{MATERIALS AND METHODS}

Male and female adult HAD1 rats $(n=12$ per sex $)$ were obtained from the Indiana University Alcohol Research center and housed individually in wire cages that were maintained in squads of 12 ( $n=6$ per sex) within a sound-shielded and lightattenuating cabinet. After a 3 week water-only adaptation period, animals were offered a free choice between $10 \%(\mathrm{v} / \mathrm{v})$ ethanol solution and plain water from separate drinking tubes, with food (Prolab 3000, Purina Mills, Inc., St. Louis, MO) available ad libitum. Licking at the ethanol tube was monitored via a contactsensing drinkometer circuit (Lafayette Instruments, Lafayette, IN), and lick totals were stored in 1-minute bins for subsequent analysis using the ClockLab interface system (Actimetrics, Inc., Evanston, IL). Unfortunately, the physical arrangement of the drinkometer circuit precluded alternation of the relative positions of the ethanol and water tubes. Ethanol and water intakes were recorded at weekly intervals.

Control animals ( $n=6$ per sex) were maintained under a stable LD 12:12 cycle throughout the study, while experimental animals $(n=6$ per sex) were subjected to repeated 6-hour LD phase advances, achieved by acute shortening the light phase of the LD cycle. 6-hour phase advances were chosen because this combination of shift magnitude and shift direction would be expected to result in relatively substantial and prolonged circadian desynchrony (Aschoff et al., 1975; Gundel and Wegmann, 1989; Leise and Siegelmann, 2006). LD phase advances recurred at 3 to 4 week intervals, and a total of 7 phase-advance shifts were administered over 26 weeks of continuous data collection. Light was produced by standard $15 \mathrm{~W}$ incandescent bulbs, positioned to yield an effective illumination of about 30 lux.

At the conclusion of behavioral testing, blood alcohol levels (BALs) were measured in trunk blood using the Analox AM1 analyzer (Analox Instruments USA, Inc., Lunenburg, MA). Animals were sacrificed for blood collection at approximately the middle of the dark segment of the LD cycle, when blood levels would be expected to be relatively high due to increased dark-phase drinking (Aalto, 1986; Agabio et al., 1996; Freund, 1970; Murphy et al., 1986). 


\section{RESULTS}

\section{Circadian Drinking Patterns}

Raster-style circadian actograms were used to examine qualitative aspects of circadian drinking (licking) patterns under control and experimental LD conditions (Fig. 1). As expected (cf., Hiller-Sturmhofel and Kulkosky, 2001), rats housed under stable LD 12:12 conditions displayed nocturnal patterns of ethanol drinking that were generally similar to the more well studied nocturnal water drinking pattern. Thus, while most ethanol drinking occurred during the dark phase, substantial drinking was also seen during the light phase. In addition, several control animals displayed progressively increasing levels of light-phase relative to dark-phase drinking over the course of the experiment, and in the most extreme case (Fig. $1 C$ ), the normal LD difference in drinking was essentially extinguished. No obvious differences were discernable between male and female drinking patterns.

Repeated exposure to 6-hour LD phase advances resulted in considerable circadian desynchrony in the experimental animals. As expected, resynchronization to the new LD cycle phase occurred gradually, and in several cases, was incomplete at the time of the next shift. In addition, several instances of "antidromic" re-entrainment (cf., Gundel and Wegmann, 1989; Leise and Siegelmann, 2006) were observed, in which adaptation to the phase-advanced LD cycle occurred via phase-delaying transients (Fig. $1 E$ and $1 F$ ). As with controls, several experimental animals showed gradual increases in the relative expression of light-phase drinking, while no
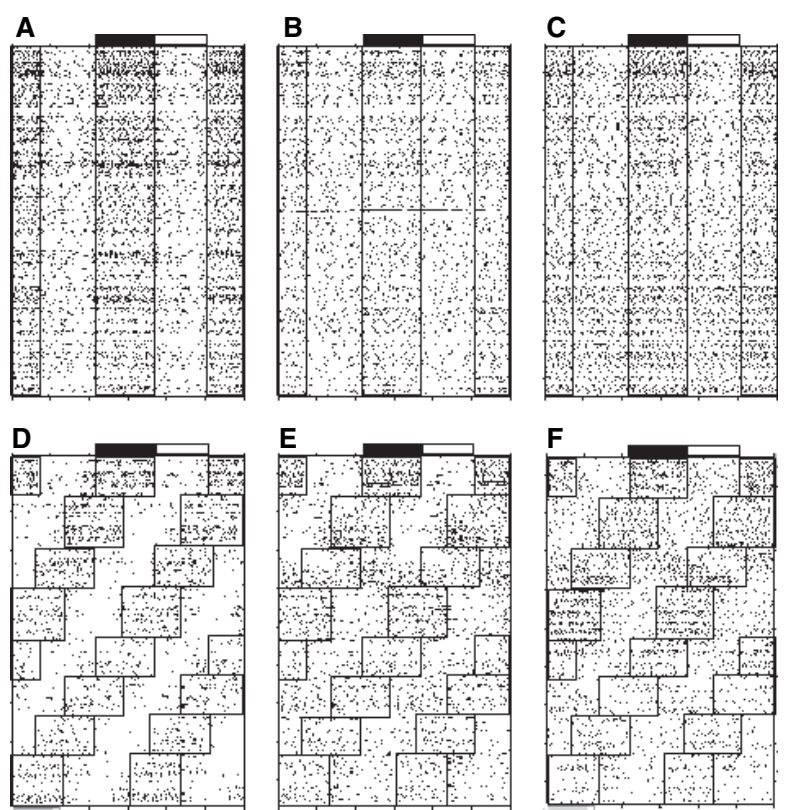

Fig. 1. Raster-style double-plotted (48-hour span) circadian actograms illustrating ethanol licking patterns in 3 representative animals from each group (control: A, B, C; experimental: D, E, F). Both females (A, D) and males $(\mathbf{B}, \mathbf{C}, \mathbf{E}, \mathbf{F})$ are shown. The superimposed rectangles enclose the dark phase of the light-dark cycle, and the initial light-dark cycle is also indicated by the horizontal bar immediately above the plots. obvious differences were seen between male and female drinking patterns.

\section{Ethanol and Water Intake}

Figure 2 shows weekly mean ethanol and water intake, and ethanol preference (i.e., 10\% ethanol intake as a proportion of total daily fluid intake), for males and females over the 26 weeks of the experiment. Considerable instability in ethanol and water intake was observed during the first 3 weeks of the experiment, but clear time-dependent trends emerged gradually. Separate three-factor ANOVAs (weeks, treatment, and sex) revealed statistically significant three-way interactions for each dependent measure (ethanol intake: $F_{25,500}=4.75, \quad p<0.001$; water intake: $F_{25,500}=2.59$, $p<0.001$; ethanol preference: $F_{25,500}=3.63, p<0.001$ ), indicating that repeated LD phase shifts resulted in complex time- and sex-dependent alterations in both ethanol and water drinking. These three-way interactions were explored further using separate two-factor (weeks $\times$ treatment) ANOVAs for each sex, which showed significant time $\times$ treatment interactions for both males and females and for each of the 3 dependent measures (all 6 p-values $<0.005$ ). Finally, these two-way interactions were examined by conducting onefactor (weeks) ANOVAs for each group (male controls, male experimental group, female controls, female experimental group) and for each dependent measure. These analyses revealed significant effects of time (weeks) on both ethanol intake and ethanol preference for all groups (all $p$-values $<0.001)$. In contrast, however, while significant effects of time on water intake were seen for both control and experimental males ( $p$-values $<0.001)$, time-dependent changes in water intake were not detected in either group of females.

Inspection of the time-dependent trends illustrated in Fig. 2 indicates that control males displayed progressively decreasing water intake, while maintaining or slightly increasing ethanol intake, thus leading to gradually increasing ethanol preference. In contrast, however, experimental males maintained their water intake, while exhibiting progressively decreasing ethanol intake and ethanol preference over the course of the experiment. These results were confirmed by subjecting the weekly means to linear regression, which revealed significant linear trends for ethanol intake in experimental males (standardized beta $=-0.693, p<0.001)$, water intake in control males (beta $=-0.910, p<0.001$ ) and ethanol preference for both control (beta $=+0.720, p<0.001$ ) and experimental (beta $=-0.557, p=0.003$ ) males.

In contrast, however, rather different effects were seen in females. Control females maintained their water intake while displaying progressive decreases in ethanol intake (beta $=$ $-0.566, p=0.003$ ) and ethanol preference (beta $=-0.499$, $p=0.009$ ) over time. Unexpectedly, experimental group females displayed markedly less ethanol intake and increased water intake than did control females, from the beginning of the experiment. Nevertheless, time-dependent trends in 

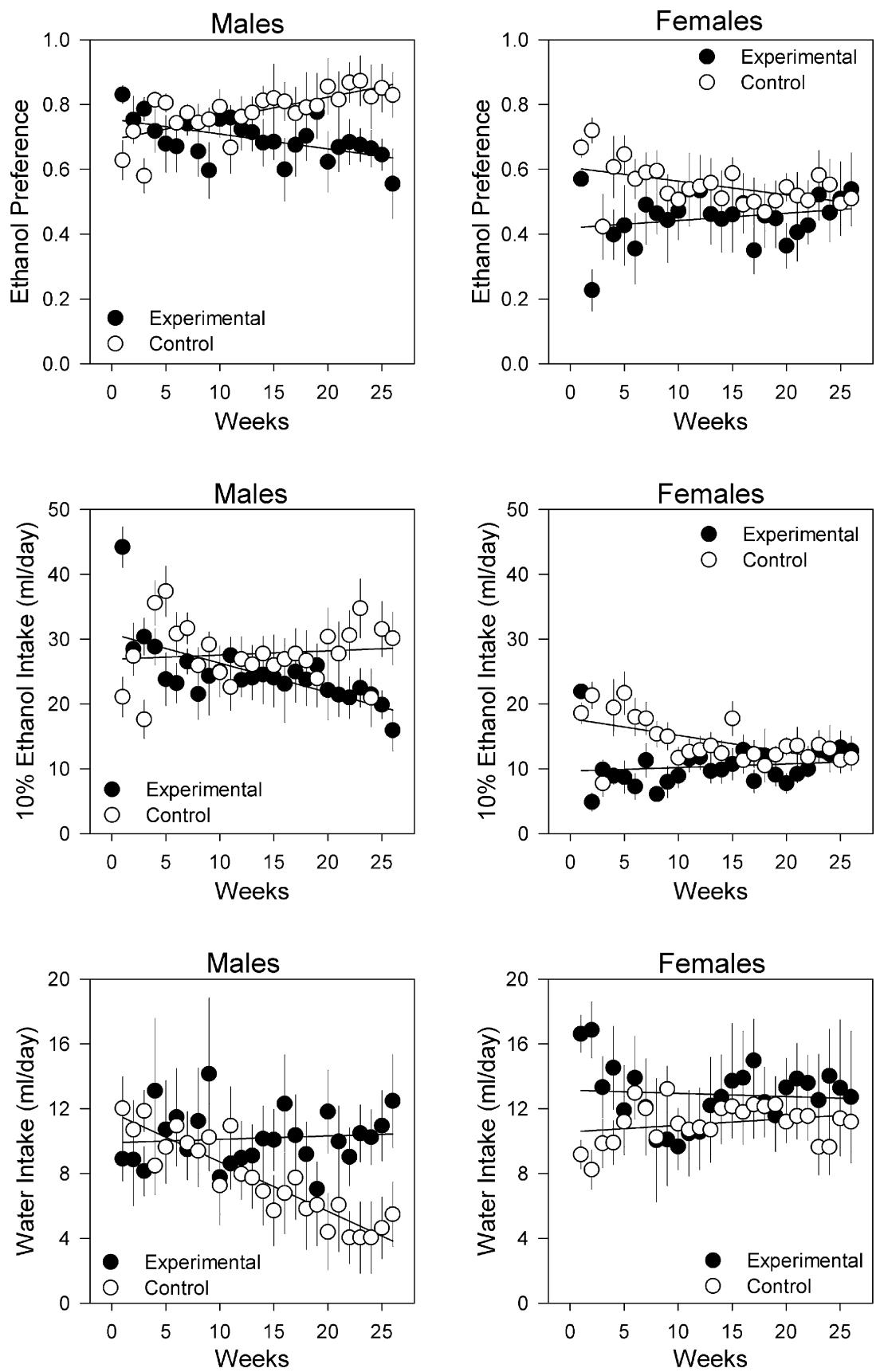

Fig. 2. Weekly mean $( \pm$ SEM) values for ethanol preference (top panels), daily ethanol intake (middle panels), and daily water intake (bottom panels) in male (left) and female (right) control (open circles), and experimental animals (closed circles). Superimposed lines were fit separately to control and experimental groups by linear regression; see text for statistical analyses.

ethanol and water drinking were different in experimental and control females, in that experimental females exhibited slight but nonsignificant increases in ethanol intake and ethanol preference over the course of the experiment.

To summarize, exposure to repeated LD phase shifts resulted in progressive decreases in ethanol intake relative to water intake in males, and appeared to oppose the progressive decreases in relative ethanol intake that occurred in control females.

\section{Acute Effects of Light-Dark Phase Shifts}

To examine possible acute changes in ethanol intake or ethanol preference resulting from LD phase shifts, data for the 3 weeks immediately preceding and the 3 weeks immediately following each shift were averaged across shifts 2 to 7 (data from the first LD shift were excluded because drinking levels were unstable during the first 3 weeks of the experiment, prior to the first shift). This analysis provided no evidence for any 


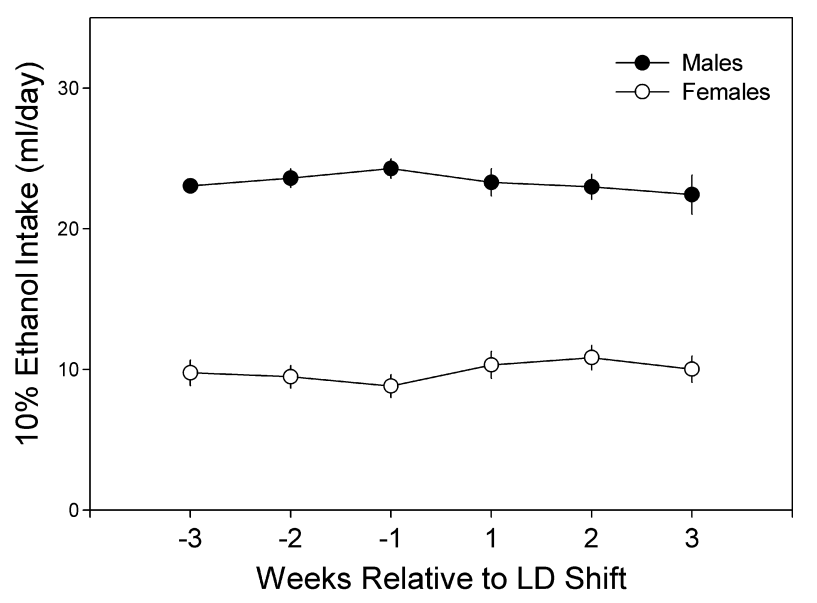

Fig. 3. Weekly mean $( \pm$ SEM) ethanol intake in male (closed circles) and female (open circles) animals in the experimental group, for the 3 weeks immediately preceding and following light-dark (LD) phase shifts, collapsed across the 7 phase shifts. The error bars represent variability across the phase shifts, not across the animals.

abrupt change in ethanol intake (Fig. 3) or ethanol preference (not shown) in the weeks immediately following LD phase shifts, and the one-factor (weeks) ANOVA failed to reveal significant changes over time in either males or females. Of course, it is possible that short-term changes occurred in the few days immediately following LD shifts that were undetectable in weekly intake totals.

\section{Blood Alcohol Levels}

Consistent with previous studies of alcohol-preferring rats under 24-hour free-access conditions (Aalto, 1986; Agabio et al., 1996; Murphy et al., 1986), BALs were variable, and ranged from near-zero to levels generally considered to be mildly intoxicating (range: 11.2 to $91.4 \mathrm{mg} / \mathrm{dl}$ ). Two-factor (treatment, sex) ANOVA revealed that BALs were significantly higher in males $\left(F_{1,18}=5.79, p=0.027\right)$, but no effects related to treatment were seen (Fig. 4, top). BALs were significantly correlated with both ethanol intake $\left(r_{20}=0.682\right.$, $p<0.001$; Fig. 4, bottom) and ethanol preference $\left(r_{20}=\right.$ $0.608, p=0.003$; not shown) as measured during the immediately preceding week, but correlation coefficients computed separately for males and females showed a significant relationship only among males $\left(r_{10}=0.654, p=0.021\right)$. Indeed, the significant relationship between BAL and alcohol intake appeared to be due mainly to the high BALs seen in the highest-intake males.

\section{DISCUSSION}

The results of this study reveal that exposure to repeated LD phase shifts results in sex-specific modulation of voluntary ethanol intake in HAD1 rats. Further, clear sex differences were seen between stably entrained male and female control animals. More specifically, repeated LD phase shifts resulted in a progressive decrease in ethanol drinking in male
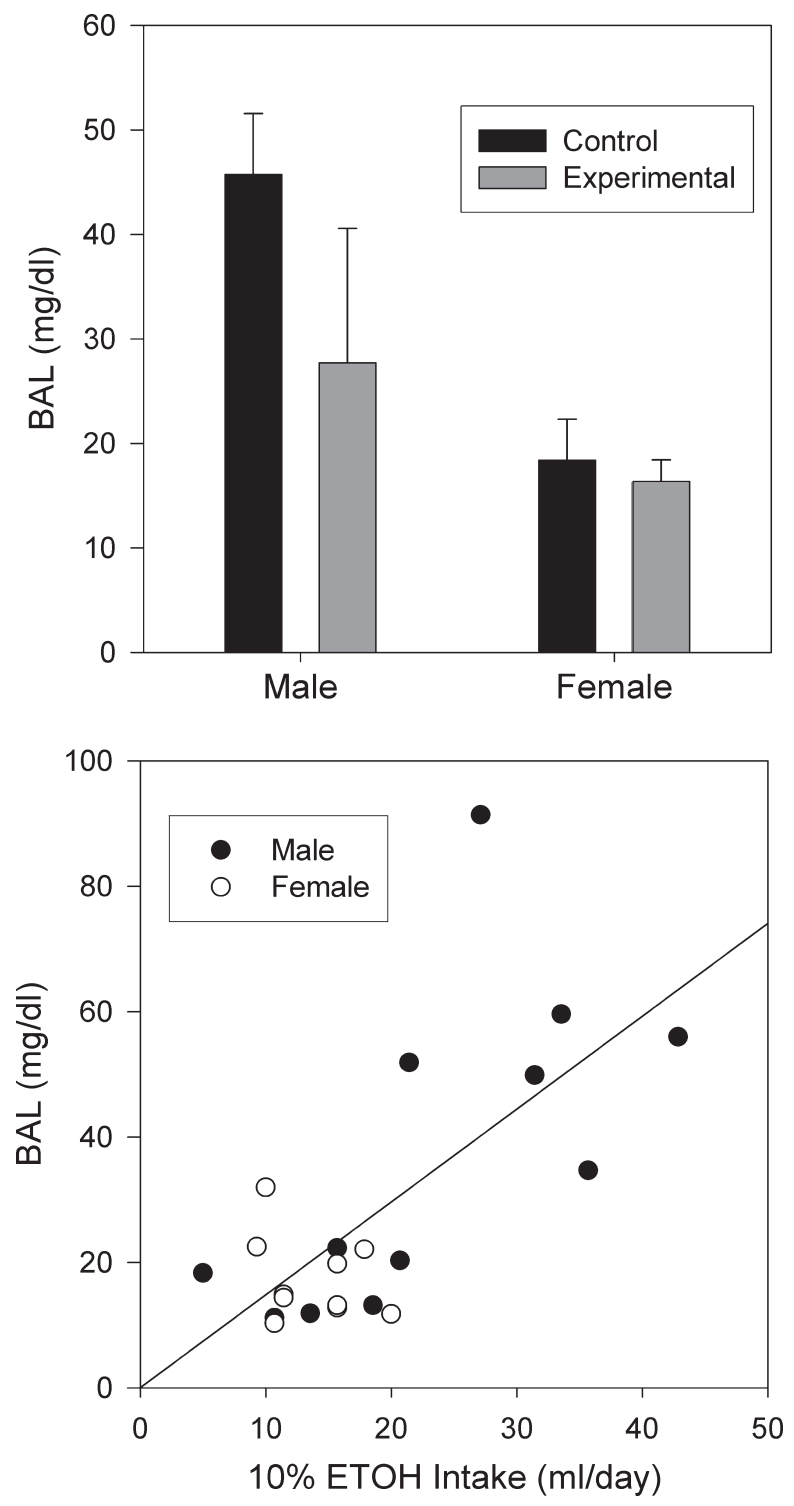

Fig. 4. Top: Mean $( \pm S E M)$ terminal blood alcohol levels (BALs) for male and female control (black bars) and experimental animals (gray bars), measured at the approximate middle of the dark phase. Bottom: Scatterplot of individual BALs as a function of mean daily ethanol intake measured during the immediately preceding week; see text for statistical analyses.

rats, relative to the gradually increasing intake displayed by male controls, while in contrast, female rats subjected to repeated LD phase shifts showed a modest increase in ethanol drinking relative to the progressive decrease seen in female controls. Similarly, we have also observed progressive increases in ethanol preference with extended exposure in male but not in female rats of the selectively-bred $\mathrm{P}$ and HAD2 lines (Fecteau et al., 2006), so the sex difference in long-term intake trends seen in control animals in the present study may be a general effect, at least among alcohol-preferring rat lines. Unfortunately, however, experimental and control females in the present experiment displayed unexpected differences in ethanol intake even before exposure to 
scheduled LD phase shifts, so the results for females must be interpreted cautiously, and should be replicated.

In humans, both shift work and transmeridian travel are associated with perturbation of normal light exposure schedules, circadian desynchrony, and sleep disruption, as well as with a wide variety of negative effects on both physical and psychological health and well-being (Boulos and Rosenwasser, 2004; Cho, 2001; Cho et al., 2000; Comperatore and Krueger, 1990; Garbarino et al., 2002; Redfern et al., 1994; Winget et al., 1984). Despite extensive evidence indicating that sleep disruption increases the likelihood of subsequent alcohol abuse in both alcoholic and nonalcoholic populations (Brower, 2001, 2003; Crum et al., 2004a,b; Wong et al., 2004), possible associations of shift work or jet lag with increased alcohol drinking have not been extensively studied. Nevertheless, there is some evidence for increased alcohol use in workers exposed to rotating work shifts (Poole et al., 1992) as well as in extreme evening chronotypes (i.e., "night owls"), who may suffer from a form of "social jet lag" even under normal entrained conditions (Wittmann et al., 2006).

In animal experiments, exposure to repeated LD phase shifts alters metabolism, immune function, tumor growth, physiological homeostasis, and longevity (Davidson et al., 2006; Filipski et al., 2004, 2005; Kort and Weijma, 1982, Kort et al., 1986; Nelson and Halberg, 1986; Penev et al., 1998; Tsai et al., 2005). While the effects of such experimental jet lag on ethanol intake have not been reported previously, other alterations in photoperiodic conditions can modulate voluntary ethanol intake (Gauvin et al., 1997; Goodwin et al., 1999; Hiller-Sturmhofel and Kulkosky, 2001; Millard and Dole, 1983), and these effects are apparently mediated in part via alterations in circadian entrainment pattern rather than by differential light exposure per se (Millard and Dole, 1983). In addition, mutation of the circadian clock gene per2 results in dramatic alterations in circadian phenotype accompanied by increased ethanol intake (Spanagel et al., 2005a,b).

The results of the present study extend these observations by demonstrating that repeated LD phase shifts also modulate voluntary ethanol intake, presumably by disrupting normal phase relationships within the circadian timing system. In contrast to initial expectations, however, circadian desynchrony was not consistently associated with increased ethanol intake. Instead, male HAD1 rats actually showed progressive decreases in ethanol intake in response to repeated LD phase shifts. Nevertheless, these results can be easily accommodated within the context of prior work on the effects of other experimental stressors on voluntary ethanol intake. Thus, both increases and decreases in ethanol intake have been reported widely, depending on the type of stressor, the history of prior stress and/or ethanol exposure, sex, genetic background of the animals, and other variables (Pohorecky, 1981, 1990, 1991; Sillaber and Henniger, 2004). One variable that has been identified repeatedly as an important modulator of stress effects on ethanol drinking is initial preference for ethanol, such that high-preferring animals are more likely to display stress induced decreases in ethanol intake, while low-preferring animals are more likely to display stress induced increases in ethanol intake. Similar relationships have been seen in selectively bred high and low ethanol-preferring lines (Chester et al., 2004), among individual animals of a genetically heterogeneous strain (Rockman and Glavin, 1986; Rockman et al., 1986; Volpicelli et al., 1990), and in response to environmental manipulation of ethanol preference (Bond, 1978). The study by Chester et al. (2004) is particularly relevant to the present results, as they reported decreased ethanol drinking in highpreferring male HAD1 rats, and increased ethanol drinking in the lower-preferring female HAD1 rats, when exposed to repeated restraint stress. Thus, apparent sex differences in stress-responsiveness seen in both Chester et al. (2004) and in the present study may be mediated by sex differences in initial ethanol preference.

In conclusion, these results support the hypothesis that chronic chronobiological disruption represents a significant source of allostatic load that may affect voluntary ethanol intake in ways that are similar to other forms of chronic stress. Nevertheless, considerable additional research will be required to fully elucidate interactions among chronobiological desynchrony, initial ethanol preference, sex, and genetic background in modulating voluntary ethanol drinking. Towards this end, we plan to extend to the present observations to include additional high and low ethanol-preferring animal models.

\section{REFERENCES}

Aalto J (1986) Circadian drinking rhythms and blood alcohol levels in two rat lines developed for their alcohol consumption. Alcohol 3:73-75.

Agabio R, Cortis G, Fadda F, Gessa GL, Lobina C, Reali R, Colombo G (1996) Circadian drinking pattern of Sardinian alcohol-preferring rats. Alcohol Alcohol 31:385-388.

Aschoff J, Hoffmann K, Pohl H, Wever R (1975) Re-entrainment of circadian rhythms after phase-shifts of the Zeitgeber. Chronobiologia 2:23-78.

Bond NW (1978) Shock induced alcohol consumption in rats: role of initial preference. Pharmacol Biochem Behav 9:39-42.

Boulos Z, Rosenwasser AM (2004) A chronobiological perspective on allostasis and its application to shift work, in Allostasis, Homeostasis, and the Costs of Physiological Regulation (Schulkin J ed), pp 228-301. Cambridge University Press, Cambridge.

Brower KJ (2001) Alcohol's effects on sleep in alcoholics. Alcohol Res Health 25:110-125

Brower KJ (2003) Insomnia, alcoholism and relapse. Sleep Med Rev 7:523539.

Chen CP, Kuhn P, Advis JP, Sarkar DK (2004) Chronic ethanol consumption impairs the circadian rhythm of pro-opiomelanocortin and period genes mRNA expression in the hypothalamus of the male rat. J Neurochem 88:1547-1554.

Chester JA, Blose AM, Zweifel M, Froehlich JC (2004) Effects of stress on alcohol consumption in rats selectively bred for high or low alcohol drinking. Alcohol Clin Exp Res 28:385-393.

Chester JA, de Paula Barrenha G, DeMaria A, Finegan A (2006) Different effects of stress on alcohol drinking behaviour in male and female mice selectively bred for high alcohol preference. Alcohol Alcohol 41:44-53.

Cho K (2001) Chronic "jet lag" produces temporal lobe atrophy and spatial cognitive deficits. Nat Neurosci 4:567-568.

Cho K, Ennaceur A, Cole JC, Suh CK (2000) Chronic jet lag produces cognitive deficits. J Neurosci 20:RC66. 
Comperatore CA, Krueger GP (1990) Circadian rhythm desynchronosis, jet lag, shift lag, and coping strategies. Occup Med 5:323-341.

Crum RM, Ford DE, Storr CL, Chan YF (2004a) Association of sleep disturbance with chronicity and remission of alcohol dependence: data from a population-based prospective study. Alcohol Clin Exp Res 28:1533-1540.

Crum RM, Storr CL, Chan YF, Ford DE (2004b) Sleep disturbance and risk for alcohol-related problems. Am J Psychiatry 161:1197-1203.

Danel T, Libersa C, Touitou Y (2001) The effect of alcohol consumption on the circadian control of human core body temperature is time dependent. Am J Physiol Regul Integr Comp Physiol 281:R52-R55.

Danel T, Touitou Y (2004) Chronobiology of alcohol: from chronokinetics to alcohol-related alterations of the circadian system. Chronobiol Int 21:923935.

Davidson AJ, Sellix MT, Daniel J, Yamazaki S, Menaker M, Block GD (2006) Chronic jet-lag increases mortality in aged mice. Curr Biol 16:R914 R916.

Dwyer SM, Rosenwasser AM (1998) Neonatal clomipramine treatment, alcohol intake and circadian rhythms in rats. Psychopharmacology (Berl) 138:176-183.

Ehlers CL, Slawecki CJ (2000) Effects of chronic ethanol exposure on sleep in rats. Alcohol 20:173-179.

Fecteau ME, Miura Y, Turner LM, Rosenwasser AM (2006) Effects of repeated cycles of ethanol access and deprivation on free-running circadian activity rhythms and voluntary ethanol intake in ethanol-preferring $(\mathrm{P}$, HAD-2) rats. Alcohol Clin Exp Res 30:84A.

Filipski E, Delaunay F, King VM, Wu MW, Claustrat B, Grechez-Cassiau A, Guettier C, Hastings MH, Francis L (2004) Effects of chronic jet lag on tumor progression in mice. Cancer Res 64:7879-7885.

Filipski E, Innominato PF, Wu M, Li XM, Iacobelli S, Xian LJ, Levi F (2005) Effects of light and food schedules on liver and tumor molecular clocks in mice. J Natl Cancer Inst 97:507-517.

Freund G (1970) Alcohol consumption and its circadian distribution in mice. J Nutr 100:30-36.

Garbarino S, Beelke M, Costa G, Violani C, Lucidi F, Ferrillo F, Sannita WG (2002) Brain function and effects of shift work: implications for clinical neuropharmacology. Neuropsychobiology 45:50 56.

Gauvin DV, Baird TJ, Vanecek SA, Briscoe RJ, Vallett M, Holloway FA (1997) Effects of time-of-day and photoperiod phase shifts on voluntary ethanol consumption in rats. Alcohol Clin Exp Res 21:817-825.

Goodwin FL, Amir S, Amit Z (1999) Environmental lighting has a selective influence on ethanol intake in rats. Physiol Behav 66:323-328.

el-Guebaly N (1987a) Alcohol, alcoholism, and biological rhythms. Alcohol Clin Exp Res 11:139-143.

el-Guebaly N (1987b) Chronobiological susceptibility to alcoholism: a hypothesis. Am J Drug Alcohol Abuse 13:449-459.

Gundel A, Wegmann HM (1989) Transition between advance and delay responses to eastbound transmeridian flights. Chronobiol Int 6:147-156.

Hiller-Sturmhofel S, Kulkosky P (2001) Chronobiological regulation of alcohol intake. Alcohol Res Health 25:141-148.

Imatoh N, Nakazawa Y, Ohshima H, Ishibashi M, Yokoyama T (1986) Circadian rhythm of REM sleep of chronic alcoholics during alcohol withdrawal. Drug Alcohol Depend 18:77-85.

Kakihana R, Moore JA (1976) Circadian rhythm of corticosterone in mice: the effect of chronic consumption of alcohol. Psychopharmacologia 46:301305.

van der Kam EL, Coolen JCM, Ellenbroek BA, Cools AR (2005) The effects of stress on alcohol consumption: mild acute and sub-chronic stressors differentially affect apomorphine susceptible and unsusceptible rats. Life Sci 76:1759-1770.

Kodama H, Nakazawa Y, Kotorii T, Nonaka K, Inanaga K, Ohshima M, Tokoyama T (1988) Biorhythm of core temperature in depressive and nondepressive alcoholics. Drug Alcohol Depend 21:1-6.

Kort WJ, Weijma JM (1982) Effect of chronic light-dark shift stress on the immune response of the rat. Physiol Behav 29:1083-1087.
Kort WJ, Zondervan PE, Hulsman LO, Weijma IM, Westbroek DL (1986) Light-dark-shift stress, with special reference to spontaneous tumor incidence in female BN rats. J Natl Cancer Inst 76:439-446.

Kubota T, De A, Brown RA, Simasko SM, Krueger JM (2002) Diurnal effects of acute and chronic administration of ethanol on sleep in rats. Alcohol Clin Exp Res 26:1153-1161.

Kuhlwein E, Hauger RL, Irwin MR (2003) Abnormal nocturnal melatonin secretion and disordered sleep in abstinent alcoholics. Biol Psychiatry 54:1437-1443.

Landolt HP, Gillin JC (2001) Sleep abnormalities during abstinence in alcohol-dependent patients. Aetiology and management. CNS Drugs 15:413425 .

Leise T, Siegelmann H (2006) Dynamics of a multistage circadian system. J Biol Rhythms 21:314-323.

Lynch WJ, Kushner MG, Rawleigh JM, Fiszdon J, Carroll ME (1999) The effects of restraint stress on voluntary ethanol consumption in rats. Exp Clin Psychopharmacol 7:318-323.

Madeira MD, Andrade JP, Lieberman AR, Sousa N, Almeida OF, PaulaBarbosa MM (1997) Chronic alcohol consumption and withdrawal do not induce cell death in the suprachiasmatic nucleus, but lead to irreversible depression of peptide immunoreactivity and mRNA levels. J Neurosci 17:1302-1319.

McClung CA, Sidiropoulou K, Vitaterna M, Takahashi JS, White FJ, Cooper DC, Nestler EJ (2005) Regulation of dopaminergic transmission and cocaine reward by the Clock gene. Proc Natl Acad Sci USA 102:93779381.

Millard WJ, Dole VP (1983) Intake of water and ethanol by C57BL mice: effect of an altered light-dark schedule. Pharmacol Biochem Behav 18:281284

Mistlberger RE, Nadeau J (1992) Ethanol and circadian rhythms in the Syrian hamster: effects on entrained phase, reentrainment rate, and period. Pharmacol Biochem Behav 43:159-165.

Murphy JM, Gatto GJ, Waller MB, McBride WJ, Lumeng L, Li TK (1986) Effects of scheduled access on ethanol intake by the alcohol-preferring $(\mathrm{P})$ line of rats. Alcohol 3:331-336.

Nagano M, Adachi A, Nakahama K, Nakamura T, Tamada M, Meyer-Bernstein E, Sehgal A, Shigeyoshi Y (2003) An abrupt shift in the day/night cycle causes desynchrony in the mammalian circadian center. J Neurosci 23:6141-6151.

Nakamura W, Yamazaki S, Takasu NN, Mishima K, Block GD (2005) Differential response of Period 1 expression within the suprachiasmatic nucleus. J Neurosci 25:5481-5487.

Nelson W, Halberg F (1986) Schedule-shifts, circadian rhythms and lifespan of freely-feeding and meal-fed mice. Physiol Behav 38:781-788.

Penev PD, Kolker DE, Zee PC, Turek FW (1998) Chronic circadian desynchronization decreases the survival of animals with cardiomyopathic heart disease. Am J Physiol 275:H2334-H2337.

Pohorecky LA (1981) The interaction of alcohol and stress. A review. Neurosci Biobehav Rev 5:209-229.

Pohorecky LA (1990) Interaction of ethanol and stress: research with experimental animals - an update. Alcohol Alcohol 25:263-276.

Pohorecky LA (1991) Stress and alcohol interaction: an update of human research. Alcohol Clin Exp Res 15:438-459.

Poole CJ, Evans GR, Spurgeon A, Bridges KW (1992) Effects of a change in shift work on health. Occup Med (Lond) 42:193-199.

Reddy AB, Field MD, Maywood ES, Hastings MH (2002) Differential resynchronisation of circadian clock gene expression within the suprachiasmatic nuclei of mice subjected to experimental jet lag. $\mathrm{J}$ Neurosci 22:7326-7330.

Redfern P, Minors D, Waterhouse J (1994) Circadian rhythms, jet lag, and chronobiotics: an overview. Chronobiol Int 11:253-265.

Rockman GE, Glavin GB (1986) Activity stress effects on voluntary ethanol consumption, mortality and ulcer development in rats. Pharmacol Biochem Behav 24:869-873.

Rockman GE, Hall A, Glavin GB (1986) Effects of restraint stress on voluntary ethanol intake and ulcer proliferation in rats. Pharmacol Biochem Behav 25:1083-1087. 
Roehrs T, Roth T (2001) Sleep, sleepiness, and alcohol use. Alcohol Res Health 25:101-109.

Rosenwasser AM (2001) Alcohol, antidepressants, and circadian rhythms. Human and animal models. Alcohol Res Health 25:126-135.

Rosenwasser AM, Fecteau ME, Logan RW (2005a) Effects of ethanol intake and ethanol withdrawal on free-running circadian activity rhythms in rats. Physiol Behav 84:537-542.

Rosenwasser AM, Fecteau ME, Logan RW, Reed JD, Cotter SJ, Seggio JA (2005b) Circadian activity rhythms in selectively bred ethanol-preferring and nonpreferring rats. Alcohol 36:69-81.

Rosenwasser AM, Logan RW, Fecteau ME (2005c) Chronic ethanol intake alters circadian period-responses to brief light pulses in rats. Chronobiol Int 22:227-236.

Rouhani S, Emmanouilidis E, Tran G, Durlach J, Payan C, Fermanian J, Manicom R, Soulairac A, Poenaru S (1990) Circadian variations in vigilance states in the alcohol-dependent rat. Physiol Behav 48:637-640.

Schmitz MM, Sepandj A, Pichler PM, Rudas S (1996) Disrupted melatoninsecretion during alcohol withdrawal. Prog Neuropsychopharmacol Biol Psychiatry 20:983-995.

Sillaber I, Henniger MS (2004) Stress and alcohol drinking. Ann Med 36:596605.

Spanagel R, Pendyala G, Abarca C, Zghoul T, Sanchis-Segura C, Magnone MC, Lascorz J, Depner M, Holzberg D, Soyka M, Schreiber S, Matsuda F, Lathrop M, Schumann G, Albrecht U (2005a) The clock gene Per2 influences the glutamatergic system and modulates alcohol consumption. Nat Med 11:35-42.
Spanagel R, Rosenwasser AM, Schumann G, Sarkar DK (2005b) Alcohol consumption and the body's biological clock. Alcohol Clin Exp Res 29:1550-1557.

Tsai LL, Tsai YC, Hwang K, Huang YW, Tzeng JE (2005) Repeated lightdark shifts speed up body weight gain in male F344 rats. Am J Physiol Endocrinol Metab 289:E212-E217.

Vengeliene V, Siegmund S, Singer MV, Sinclair JD, Li TK, Spanagel R (2003) A comparative study on alcohol-preferring rat lines: effects of deprivation and stress phases on voluntary alcohol intake. Alcohol Clin Exp Res 27:1048-1054

Volpicelli JR, Ulm RR, Hopson N (1990) The bidirectional effects of shock on alcohol preference in rats. Alcohol Clin Exp Res 14:913-916.

Winget CM, DeRoshia CW, Markley CL, Holley DC (1984) A review of human physiological and performance changes associated with desynchronosis of biological rhythms. Aviat Space Environ Med 55: 1085-1096.

Wittmann M, Dinich J, Merrow M, Roenneberg T (2006) Social jetlag: misalignment of biological and social time. Chronobiol Int 23:497-509.

Wong MM, Brower KJ, Fitzgerald HE, Zucker RA (2004) Sleep problems in early childhood and early onset of alcohol and other drug use in adolescence. Alcohol Clin Exp Res 28:578-587.

Yamazaki S, Numano R, Abe M, Hida A, Takahashi R, Ueda M, Block GD, Sakaki Y, Menaker M, Tei H (2000) Resetting central and peripheral circadian oscillators in transgenic rats. Science 288:682-685. 